\title{
Perineural Cyst
}

National Cancer Institute

\section{Source}

National Cancer Institute. Perineural Cyst. NCI Thesaurus. Code C4797.

Cyst of the nerve roots filled with cerebrospinal fluid, usually located in the sacral area of the spine. 